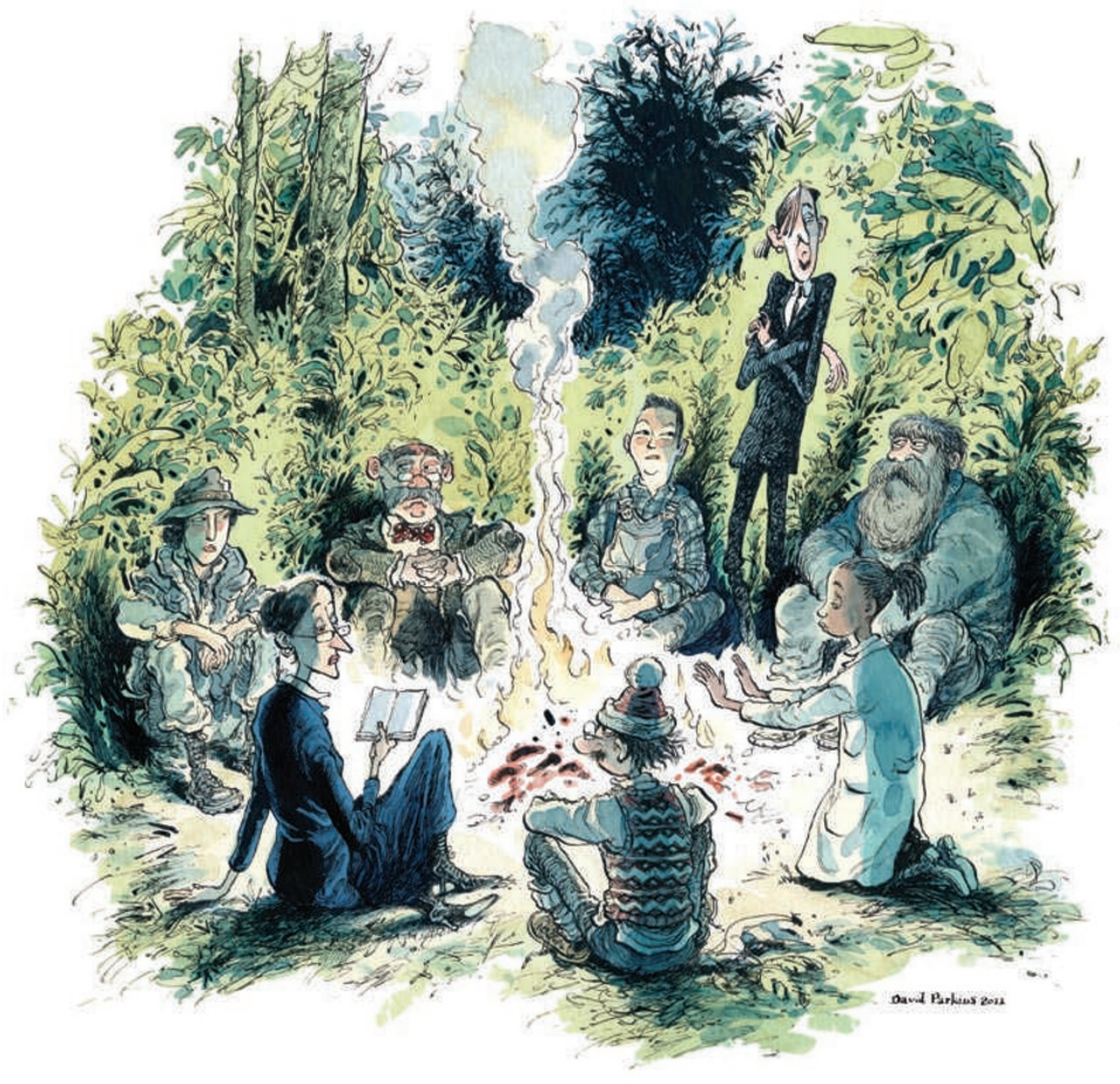

\title{
Anthropologists unite!
}

\section{Anthropology isn't in the crisis that parts of the media would have you believe, but it must do better, argue Adam Kuper and Jonathan Marks.}

I n December 2010, The New York Times reported $^{1,2}$ that the term 'science' had been dropped in a new long-range plan of the American Anthropological Association (AAA). Where once the association had dedicated itself "to advance anthropology as the science that studies humankind in all its aspects", it now promised rather "to advance public understanding of humankind in all its aspects".

The reporter suggested that this brought to a head an epic struggle in the discipline between the true scientists and their foes. Frank Marlowe, president-elect of the Evolutionary Anthropology Society (a branch of the AAA that is curiously independent of its long-standing Biological Anthropology Section), was quoted as saying: "we evolutionary anthropologists are outnumbered by the new cultural or social anthropologists, many but not all of whom are postmodern, which seems to translate into antiscience."

The new long-range plan also provoked rumblings of discontent (still ongoing) in the blogosphere, and the association's executive committee scrambled somewhat belatedly to reassure the public - and its own members - that it had all been a misunderstanding. They had not intended to cast doubt on the scientific character of the discipline. And in fact the same committee had come up with a simultaneous text entitled 'What is Anthropology?', which describes anthropology unambiguously as a science.

Apparently, a committee had floundered in trying to come up with an agenda for anthropology that was baggy enough to accommodate its very various research programmes. Is this news? Indeed it is, but not, as the bloggers and The New York Times suggest, because an anti-science conspiracy has hijacked American anthropology. The real shocker is that anthropologists cannot agree on what the discipline is about. Many, probably most, anthropologists have walked away from their traditional mission, which is to build a truly comparative science of human variation. We need to work out where we are now heading.

\section{ROOTS AND BRANCHES}

The reason that the AAA got into such a pickle is that - like geography, even perhaps like biology - anthropology is a nineteenthcentury discipline that fragmented, spawning a variety of specializations. Biological anthropology, archaeology and the various traditions of ethnography are bundled together in many university departments and professional associations such as the AAA and, in Britain, the Royal Anthropological Institute. However, relationships are often distant. The biologists do genetics, or neuroscience, or primatology, or chase up 
new developments in evolutionary theory. They show little interest in archaeology - except perhaps the archaeology of very ancient humans - or in ethnography, except for snippets of information about sex and violence. Some do seem to feel that if only they could spare the time they would be able to knock some evolutionist sense into cultural anthropology. But they are too busy.

Meanwhile, the ethnographers agree that their first task is to document the great diversity of human ways of life. Generalizations about human nature should not be based on a single report of Amazonian violence, or Tibetan polyandry, or woman-woman marriage among the Lovedu of South Africa. But they do not agree on how to make sense of the customs of faraway peoples. Social anthropologists engage with models and theories current in the social sciences (ideally, although they seldom keep up as well as they should). Some cultural anthropologists aim rather to understand and translate, and they look for inspiration to literary theorists and philosophers (preferably French, even if they have to be read in often impenetrable translations).

For a long time the main branches of anthropology largely ignored one another, but in the 1980s two radical movements provoked a confrontation. Sociobiologists claimed that genetics was about to revolutionize the human sciences. These would become at last a branch of biology, although the great biologist Ernst Mayr did warn that "the profound differences in social behaviour among human groups, some of them closely related, show how much of this behaviour is cultural rather than genetic". Sociobiologists also drew on ethology,

an older movement

that made much of

parallels between

human and primate

- or even insect -

behaviour, provoking

Sherwood Washburn,

a leading biological

"The real

shocker is that anthropologists cannot agree what the discipline is about."

anthropologist, to

comment that human ethology "might be defined as the science that pretends humans cannot speak".

Inspired by the elegant essays of Clifford Geertz, another new movement appeared centre-stage in the 1980s (in fact another very old movement, in modern dress). Cultural theorists, identifying themselves with the humanities, insisted that foreign ways of thought are resistant to translation, that variation and change characterize even the most isolated populations, and that it is therefore not easy to say what the Bushmen do, or the Trobrianders, or for that matter the English (all of them? Always?), so comparisons are problematic. Some disciples of
Geertz followed that road down to a relativist dead end. All generalizations about human beings were suspect, except for the iron law that culture trumps biology ${ }^{3}$.

The controversies of the 1980s, which lingered on into the 1990s, often hinged on claims about race, sex and violence, and so they caught the attention of a wider public. In a popular book published in 1928, Margaret Mead had reported that Samoan girls enjoyed sexual freedom, and so experienced an untroubled passage through adolescence $^{4}$. More than half a century later (and after Mead's death), Derek Freeman trashed her account, insisting that the girls were remarkably chaste ${ }^{5}$. Rather mysteriously, the sex life of Samoan girls became a popular test-case for the nature-nurture argument. (Recent commentaries are kinder to Mead than to Freeman, although it has become obvious that neither Freeman nor Mead can be relied on uncritically for the description of Samoan adolescence, let alone for the explanation ${ }^{6}$.)

Young women might find happiness in a liberated sex life, but were young men given rather to violence? Napoleon Chagnon claimed that among the Yanomami of the Amazon, the most violent men got the girls. (And he suggested that, in something like a state of nature, all men are Yanomami under the skin ${ }^{7}$.) His account of these people was challenged by other ethnographers, who reported significant local variation even among the 22,500-strong Yanomami, not least in rates of homicide and the abduction of women ${ }^{8}$. In any case, the Yanomami are not typical even of the most isolated, smallscale, technologically limited societies. Many ethnographies document easy-going gender relationships between hunter-gatherers, from Alaska to the Kalahari Desert, or offer historical accounts of peace-loving Indian chiefs with many wives, presiding over a monastic soldiery.

Race was altogether a more serious matter, but on this the anthropologists were not fundamentally divided. The 1994 publication by psychologist Richard J. Herrnstein and political scientist Charles Murray of their book The Bell Curve $e^{9}$ provoked a national debate about race and inequality. The AAA and the American Association of Physical Anthropologists issued parallel statements summarizing the scientific understanding on race. In brief, they agreed that human variation is structured bioculturally, clinally and locally. Nothing corresponding to the zoological subspecies exists within extant Homo sapiens. Individuals and groups of people do indeed differ biologically. However, social inequalities are overwhelmingly the product of political and economic history, not of microevolution.

In the course of the feuding 1980s, several flagship anthropology departments in the United States split up. The biologists joined faculties of science or medicine. Cultural anthropologists allied themselves with the humanities. Archaeologists sought shelter where they could. In Europe the main branches of anthropology had gone their own ways after the Second World War. It now seemed as though the Americans were belatedly following the same route. However, in the new millennium, the brief and localized trend reversed itself. This is because there is a student demand for the whole package, the study of human origins, history and diversity.

Today, anthropologists may teach more or less happily in interdisciplinary teams, but they seldom collaborate in research projects that breach their disciplinary specialities. In the past few years
"There

is aneed

for a truly comparative

science of human beings throughout their history, and all over the world." they have drifted to a sadder-but-wiser default position, some documenting the range of differences in human biology, others studying the world of social institutions and belief systems. Only a handful still try to understand the origins and possible connections

between biological, social and cultural forms, or to debate the relative significance of history and microevolution in specific, well-documented instances.

This is a great pity, and not only because the silence of the anthropologists has left the field to blockbusting books by amateurs that are long on speculation and short on reliable information. Anthropologists hardly bother any longer to take issue with even the most outlandish generalizations about human nature. Not their business.

\section{BETTER TOGETHER}

To be sure, it is not easy to make general statements about human nature, or even to define it. One obstacle is the often-taken-forgranted opposition between the notoriously - perhaps necessarily - unstable ideas of 'nature' and 'culture. The human species has been co-evolving with technology for millions of years. Advances in contraceptive techniques have transformed our sexual behaviour. The most fundamentally hardwired human adaptations - walking and talking - are actively learned by every person, in each generation. So whatever human nature may be, it clearly takes a variety of local forms, and is in constant flux.

The obvious conclusion is that interdisciplinary research is imperative. Yet too few biological anthropologists attend to social or cultural or historical factors. A minority of cultural anthropologists and archaeologists do apply evolutionary theory, or cognitive science, or adopt an ecological 
perspective on cultural variation, or play about with the theory of games, but they feel that they are isolated, even marginalized. And they do not feature in the front line of current debates about cognition, altruism or, for that matter, economic behaviour or environmental degradation, even though these debates typically proceed on the basis of very limited reliable information about human variation. A rare exception is the field of medical anthropology, where cultural anthropologists engage regularly with biologists in studies of HIV and AIDS, or posttraumatic stress disorders, or investigations of folk medical beliefs and practices.

Yet even allowing for their current headdown posture, anthropologists do share a great common cause. They would agree that anyone who makes claims about human nature must learn a lot of ethnography. This does not mean parachuting into the jungle somewhere to do a few psychological experiments with the help of bemused local interpreters, or garnishing generalizations with a few worn and disputed snippets about exotic customs and practices. Unfor-

$\rightarrow$ NATURE.COM For more on working in anthropology see: go.nature.com/3n11uo

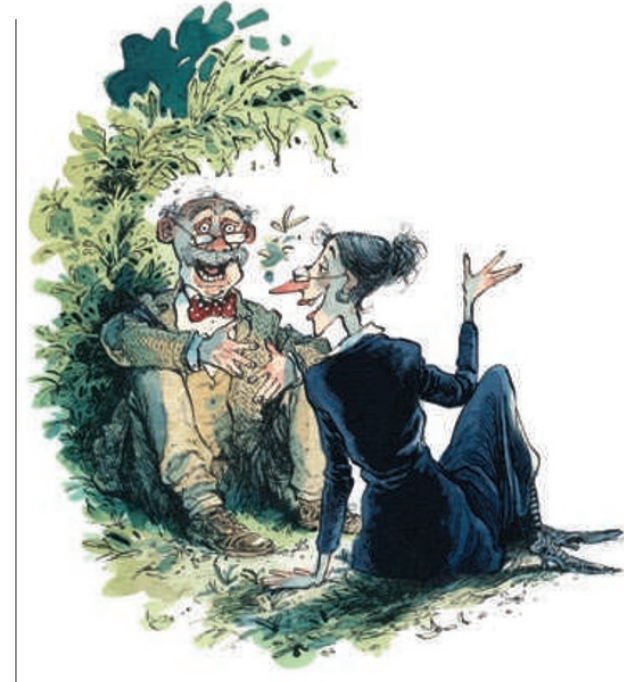

North America and the European Union. Ninety-six per cent of the subjects of studies reported in the leading American psychology journals are drawn from Western industrial societies ${ }^{10}$. These represent a minuscule and distinctly non-random sample of humanity.

So there is a need for a truly comparative science of human beings throughout their history, and all over the world. This requires more interdisciplinary team research in anthropology. A good start would be for anthropologists to read each other's papers, to attend each other's conferences and to debate concrete cases and specific hypotheses. But there is no future in a return to the feuding parties of the 1980s.

Adam Kuper is a visiting professor at the Department of Anthropology, London School of Economics, London WC2A 2AE, UK.

Jonathan Marks is in the Department of Anthropology, University of North Carolina-Charlotte, Charlotte, North Carolina 28223, USA. e-mail:adam.kuper@gmail.com

1. Wade, N. Anthropology a science? Statement deepens a rift. New York Times (9 December 2010).

2. Wade, N. Anthropology group tries to soothe tempers after dropping the word 'science'. New York Times (13 December 2010).

3. Kuper, A. Culture: The Anthropologists' Account (Harvard Univ. Press, 1999).

4. Mead, M. Coming of Age in Samoa (William Morrow, 1928).

5. Freeman, D. Margaret Mead and Samoa (Harvard Univ. Press, 1983).

6. Shankman, P. The Trashing of Margaret Mead: Anatomy of an Anthropological Controversy (Univ. Wisconsin Press, 2009).

7. Chagnon, N. A. Science 239, 985-992 (1988).

8. Albert, B. Curr. Anthropol. 30, 637-640 (1989).

9. Herrnstein, R. J. \& Murray, C. The Bell Curve: Intelligence and Class Structure in American Life (Free Press, 1994).

10.Arnett, J. J. Am. Psychol. 63, 602-614 (2008). 